\title{
Growth and development of komatsuna (Brassica rapa L. Nothovar) in NFT (nutrient film technique) system, as influenced by natural mineral
}

\author{
Abul Kalam Azad ${ }^{1,2 *}$, Katsumi Ishikawa ${ }^{1}$, Juan Carlos Diaz-Perez ${ }^{3}$, Touria El-Jaoual Eaton ${ }^{4}$, \\ Noriko Takeda ${ }^{1}$ \\ ${ }^{1}$ Laboratory of Biological and Environmental Systems, Kochi University, Nankoku-shi, Japan; \\ *Corresponding Author: azad.adrinwa@gmail.com \\ ${ }^{2}$ Department of Crop Science and Technology, Rajshahi University, Rajshahi, Bangladesh \\ ${ }^{3}$ Department of Horticulture, University of Georgia, Tifton, USA \\ ${ }^{4}$ Department of Plant, Soil and Insect Sciences, University of Massachusetts, Amherst, USA
}

Received 16 May 2013; revised 17 June 2013; accepted 3 July 2013

Copyright (C) 2013 Abul Kalam Azad et al. This is an open access article distributed under the Creative Commons Attribution License, which permits unrestricted use, distribution, and reproduction in any medium, provided the original work is properly cited.

\section{ABSTRACT}

The cultivation of komatsuna (Brassica rapa $L$. Nothovar) was carried out hydroponically using a nutrient film technique (NFT) system inside a greenhouse, applying a quartz porphyry (QP) treated nutrient solution. Quartz porphyry is a natural mineral containing many substances that easily ionize with water to improve water quality. Different growth attributes of komatsuna such as leaf length, leaf width and plant fresh weight increased in plants that received QP treated nutrient solution. The coefficient of variation was smaller for QP treated nutrient solution plants when compared to the control. High light intensity, long duration of solar radiation and higher temperatures in the summer (JulyAug.) promoted plant growth compare to winter (Dec.-Feb.). In contrast, plants grown in the winter accumulated more fresh weight compare to plants grown in the summer. Results also showed that the rapid exchange of ion in the nutrient solution due to the QP treatment enabled the solution to maintain the ion balance, and thus plants grew uniformly and vigorously. The cations $\mathrm{Na}^{+}$and $\mathrm{Ca}^{2+}$ and the anions $\mathrm{Cl}^{-}$and $\mathrm{SO}_{4}^{2-}$ were dominant and made the media saline. There was a decrease of $\mathrm{Na}^{+}$ion concentration in the recirculating nutrient solution (NFT) due to ion exchange by QP. Results suggest that water treatment with QP could be used for production of high quality vegetables.

Keywords: Water Treatment; Cations; Anions; Ion
Balance; Komatsuna Cultivation

\section{INTRODUCTION}

There is an increasing need to recirculate and reuse nutrient solutions in hydroponics in order to reduce environmental and economic costs. However, one of the weakest points in hydroponics is the lack of information on managing the nutrient solution [1]. The basic laboratory techniques of nutrient solution culture were developed (independently) by Sachs and Knap in Germany about 1860 [2]. Therefore, control over the concentration and composition of the nutrient solution in hydroponics culture is very important. So, care is required not to allow salt concentrations in the nutrient solution to become too high, nutrients to become too depleted, or $\mathrm{pH}$ to wander far from the desired value.

An NFT (nutrient film technique) system of hydroponics culture can be used to manage the nutrient solution and stabilize the annual cultivation of vegetable crops. NFT is a modern hydroponic method that involves the usage of a shallow film of nutrient solution to flow past the plant roots [3]. Instead of having to compete with other plants for nutrients in the soil, hydroponic plants thrive on a nutrient solution which contains all the essential elements. Plants in hydroponics grow more rapidly than plants in soil because they have direct access to essential plant nutrients and water.

Development of new technology using very small amounts of minerals is important for agriculture ecosystem sustainability. Quartz porphyry is a rock mainly consisting of alkali feldspar and quartz. This rock is distinct for its enormous porosity, high absorption capacity, and 
its ability to release natural minerals contained in the stone itself. Ishikawa et al., [4] described the physical and chemical properties of QP in the activation of water in agriculture. Researchers have reported the effects of water quality on plant growth [5-7]. There are reports that QP can regulate $\mathrm{pH}$ and remove harmful pollutants from water while leaving important trace elements and minerals essential to plants [8].

The QP, having electrical and $\mathrm{pH}$ dependent charges at the surface has been reported to contribute to improving water quality [9] and $\mathrm{pH}$-buffer capacity [10]. The objective of this experiment was to determine the effects of QP treated nutrient solution on the growth and development of komatsuna (Brassica rapa L. Nothovar) cultivated in an NFT hydroponics system.

\section{MATERIALS AND METHODS}

\subsection{Quartz Porphyry}

The QP rocks collected from Gifu prefecture, Japan, were crushed into pieces (10 to $15 \mathrm{~mm}$ diameter). The physical properties of porous QP were as follows: specific gravity $=2.636$; coefficient of water conductivity $(\mathrm{cm} / \mathrm{s})=0.149$; and specific surface area $\left(\mathrm{m}^{2} / \mathrm{g}\right)=3.67$. The QP rocks contain the following exchangeable cations: $\mathrm{Na}^{+}$(0.06 meq/100g), $\mathrm{K}^{+}(0.13 \mathrm{meq} / 100 \mathrm{~g}), \mathrm{Ca}^{2+}(1.10$ $\mathrm{meq} / 100 \mathrm{~g})$, and $\mathrm{Mg}^{2+}(0.28 \mathrm{meq} / 100 \mathrm{~g})$.

\subsection{Treatment System}

The treatment system was a 400-L reinforced fiber plastic (RFP) tank equipped with a stainless steel container, an air pump, and a submerged pump (Figure 1). In the treatment section, $10 \mathrm{~kg}$ of crushed QP was placed inside the stainless steel layer of the container $\left(0.3 \mathrm{~m}^{3}\right.$ volume). The nutrient solution was pumped through the layer using the submerged pump. Pressurized air was pumped from the lower layer to the upper layer of the stainless steel container.

\subsection{Nutrient Film Technique (NFT) System}

NFT is a system for plant growth in a slow constant flow of nutrient enriched water to the roots immersed in sloped channels [11]. In our experiment, the NFT growing system was set on a table like flat surface, with 5 channels ( 1 to $3 \mathrm{~mm}$ deep) that run lengthwise across its surface. It was about $0.9 \mathrm{~m}$ high, $11 \mathrm{~m}$ long, $0.6 \mathrm{~m}$ wide. The nutrient solution stream was then fed to the plants via a submersible pump at a flow rate of $0.3 \mathrm{~m}^{3} / \mathrm{h}$. By switching on the submerged pump, it released nutrient solution from the RFP container to one end of the NFT table causing the stream to spread evenly to each channel, flowing downward and submersing each plant in a nutrient solution of approximately $1-3 \mathrm{~mm}$ in depth. Once the stream reached the end of the table it was caught in the reservoir at the bottom of the tank and re-circulated. The $300 \mathrm{~L}$ of nutrient solution was added to the RFP tank as replenishment at 4-day intervals for the first two weeks, and at 3-day intervals for the last two weeks of the seedlings growth period for both treatment and control. A water level sensor with magnetic valve maintained the water level in the tank.

The $\mathrm{pH}$ of nutrient solution was adjusted to 5.0 to 7.0 , and EC to 2.5 to $3.0 \mathrm{dS} / \mathrm{m}$. Diluted sulfuric acid $(1 \mathrm{~N}$ $\left.\mathrm{H}_{2} \mathrm{SO}_{4}\right)$ and alkali $(1 \mathrm{~N} \mathrm{NaOH})$ were used for adjusting $\mathrm{pH}$, and for maintaining $\mathrm{EC}$ values, we added either more nutrients to increase the EC or more water to lower the EC. The source of the nutrient solutions was Mikade (a Japanese Company named Mikado; Location: Mikado Kyowa Seed Co. Ltd., 377 Ozawa, Chonan-machi, Chosei-gun, Chiba 297-0142, Japan) in its No.1 and No.

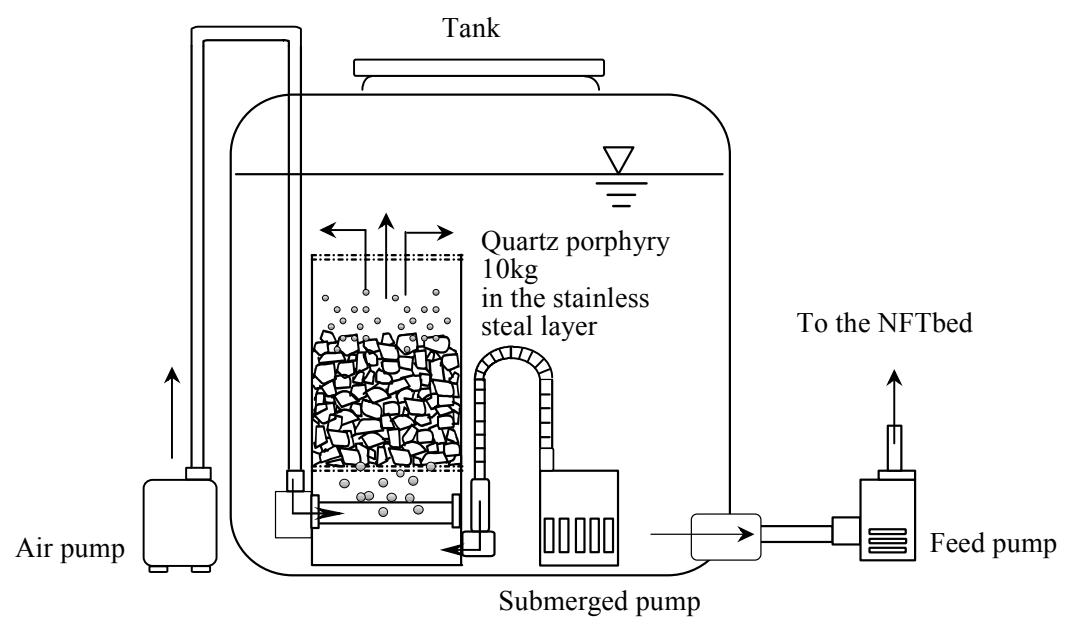

Figure 1. Quartz porphyry (QP) water treatment system used for growing komatsuna (Brassica rapa L.) hydroponically in Kochi University, Nankoku city, Japan in different seasons from April 01, 2007 to February 27, 2008. 
2 (Table 1) solutes.

\subsection{Experimental Design}

The experimental design for NFT involved two treatments, a QP treatment and a control. Treatments were arranged in a randomized complete block (RCB) design in 2 hydroponic vessels. For the control, tap water with nutrient solution was used for growing seeds and seedlings in one hydroponic vessel. In the QP treatment, QP treated nutrient solution was applied to another hydroponic vessel from a separate RFP tank.

\subsection{Cultivation of Komatsuna}

Greenhouse air temperature, nutrient solution temperature, and $\mathrm{pH}$ and $\mathrm{EC}$ values of both nutrient solutions were recorded on alternate days at 10:00 am during the cultivation period (Table 2). Sidewall and/or roof vents were used to cool the air and reduce relative humidity.

Table 1. Different nutrient components of Mikado (Mikado no. 1 and 2) fertilizer.

\begin{tabular}{cc}
\hline Components & Content (\%) \\
\hline Mikado No. & 10.0 \\
Total-N & 1.5 \\
$\mathrm{NH}_{4}-\mathrm{N}$ & 8.2 \\
$\mathrm{NO}_{3}-\mathrm{N}$ & 8.0 \\
$\mathrm{PO}_{4}-\mathrm{P}$ & 26.0 \\
$\mathrm{~K}^{+}$ & 4.0 \\
$\mathrm{Mg}^{2+}$ & 0.1 \\
$\mathrm{Mn}^{2}$ & 0.1 \\
$\mathrm{~B}$ & \\
$\mathrm{Mikado} \mathrm{No.} 2^{2+}$ & 11.0 \\
\hline
\end{tabular}

Greenhouse temperature was controlled by ventilation, switching the side windows at different times of the day. Komatsuna seeds were germinated in urethane/sponge made cube (Ice Tray Mould, Zehjiang, China) at $25^{\circ} \mathrm{C}$ inside a growth chamber. After a 4-day germination period, seedlings $(1 \mathrm{~cm}$ tall) were transplanted to styrofoam (Silicone Rubber Ice Cube Tray, Shanghai Rui Lan Mgf. Co., Ltd, Shanghai, China) nursery boxes divided into the two treatments during different seasons from April 01, 2007 to February 27, 2008. Each experimental group had 10 nursery boxes containing 50 holes in each of them and was placed on the NFT cultivation bed in the greenhouse. The roots of each komatsuna plant were fixed in a sponge made root cube and placed in pre-drilled holes of the nursery boxes within the gullies. The plant spacing or hole to hole distance was $12 \mathrm{~cm} \times 12 \mathrm{~cm}$. Leaf length was measured every 4 days in the whole cultivation period to determine leaf growth rate. Komatsuna plants were harvested 4 weeks after transplanting of the seedlings. At harvest, 50 plants (five plants from each sheet) were picked randomly as samples for the spring, summer, autumn, and winter cultivation. Leaf length, leaf width and plant fresh weight were measured immediately after harvest. The experiment was conducted three times in each season.

\subsection{Analysis of Water}

The $\mathrm{pH}$ and EC of water samples were measured using pH (PHL-10, DKK) and EC (TOA-DKK) meters. Ion concentration in both control and treated water samples were determined with an ion analyzer [IA-100 (TOA DKK)] (DKK-TOA Corporation, 29 - 10, 1-Chome, Takadanobada, Shinjuku-Ku, Tokyo 169 - 8648, Japan). The concentrations of cations such as $\mathrm{Na}^{+}, \mathrm{K}^{+}$and $\mathrm{Ca}^{2+}$ and anion such as $\mathrm{Cl}^{-}, \mathrm{NO}_{3}^{-}$and $\mathrm{SO}_{4}^{2-}$ were determined immediately after collecting the nutrient solution samples.

Although ion concentration was measured in $\mathrm{mg} / \mathrm{L}$, values were converted to meq/L using the formula:

Table 2. pH, EC, and temperature of the hydroponic nutrient solution and greenhouse of Kochi University, Nankoku city, Japan in different seasons from April 01, 2007 to February 27, 2008.

\begin{tabular}{|c|c|c|c|c|c|c|c|c|}
\hline & \multicolumn{2}{|c|}{ Spring } & \multicolumn{2}{|c|}{ Summer } & \multicolumn{2}{|c|}{ Autumn } & \multicolumn{2}{|c|}{ Winter } \\
\hline & Control & Treatment & Control & Treatment & Control & Treatment & Control & Treatment \\
\hline \multicolumn{9}{|c|}{ Nutrient Solution } \\
\hline $\mathrm{pH}$ & $6.7(0.03)$ & $6.7(0.02)$ & $6.7(0.04)$ & $6.7(0.01)$ & $7.3(0.04)$ & $7.4(0.03)$ & $7.5(0.05)$ & $7.6(0.02)$ \\
\hline $\mathrm{EC}(\mathrm{ds} / \mathrm{m})$ & $2.3(0.04)$ & $2.2(0.01)$ & $2.6(0.03)$ & $2.6(0.02)$ & $2.0(0.05)$ & $2.1(0.02)$ & $1.9(0.06)$ & $2.0(0.03)$ \\
\hline \multicolumn{9}{|c|}{ Temperature } \\
\hline Nutrient Solution $\left({ }^{\circ} \mathrm{C}\right)$ & \multicolumn{2}{|c|}{$22.7(0.02)$} & \multicolumn{2}{|c|}{$32.0(0.05)$} & \multicolumn{2}{|c|}{$23.0(0.03)$} & \multicolumn{2}{|c|}{$14.2(0.04)$} \\
\hline Greenhouse Temp. $\left({ }^{\circ} \mathrm{C}\right)$ & \multicolumn{2}{|c|}{$19.6(0.03)$} & \multicolumn{2}{|c|}{$29.2(0.04)$} & \multicolumn{2}{|c|}{$22.5(0.02)$} & \multicolumn{2}{|c|}{$10.2(0.05)$} \\
\hline
\end{tabular}

Each value indicates the average of three (3) trials with standard deviation in parentheses. 


$$
\text { meq } \mathrm{L}^{-1}=\mathrm{mg} \mathrm{L}^{-1} / \text { eq wt }
$$

where, eq wt is the equivalent weight of the constituent ion [12].

The following equivalent weights of constituents in water were used: $\mathrm{Na}^{+}(23), \mathrm{K}^{+}(39), \mathrm{Ca}^{2+}(20), \mathrm{Cl}^{-}$(35.5), $\mathrm{NO}_{3}^{-}(62)$ and $\mathrm{SO}_{4}^{2-}$ (48).

\subsection{Statistical Analysis}

Data from each experiment were analyzed separately by analysis of variance (ANOVA) using Duncan's multiple range test [13]. Least significant differences $(\mathrm{P}=0.05$, $\mathrm{P}=0.01)$ were calculated for variables exhibiting significance in the ANOVA.

\section{RESULTS AND DISCUSSION}

\subsection{Environmental Conditions}

The temperature of the nutrient solution (mean $=23.0$ ${ }^{\circ} \mathrm{C}$ ) was about $2.6^{\circ} \mathrm{C}$ higher than air temperature (mean = $20.4^{\circ} \mathrm{C}$ ). The $\mathrm{pH}$ and $\mathrm{EC}$ of the treatment nutrient solutions were similar to those of control (Table 2). Values of $\mathrm{pH}$ and $\mathrm{EC}$ varied among seasons. The average values of EC were lower than $2.5 \mathrm{dS} / \mathrm{m}$ in all seasons except in summer, and distinct differences in EC values occurred from one season to another. EC is dependent on temperature, $\mathrm{EC}$ increases as the temperature increases (for example $2 \%$ increase of EC per $1{ }^{\circ} \mathrm{C}$ ) [14].

Komatsuna plants grew vigorously in summer (JulyAug.), due to high irradiance, long day length and high air temperature, and less vigorously in the winter (Dec.Feb.) (Table 3). Al-Ghamdi and Al-Tahir [15] reported similar findings that high crop growth rates occurred during the vegetative period because of high percentage radiation interception, however, low crop growth rates during grain filling because of low incident radiation. In low light conditions (overcast days or indoor growing environments), the plants took up more potassium and phosphorous from the nutrient solution, on the other hand, in strong intense light (clear sunny days) plants took up more nitrogen from the nutrient solution [16].

\subsection{Ion Analysis}

Ion concentrations in the control and QP treated nutrient solution were determined for the whole year (Table 4). The value for each month is an average value for 30 days (15 measurements per month). Coefficient of variation in annual cation and anion concentrations were smaller in treated solution compared to control (Figures 2(a) and (b)). Smaller values of coefficient of variation indicate lower variation within unit of the same population i.e. smaller coefficient of variation refers to as homogenous variability of ion concentrations or plant growth (Table 3). A homogeneous variation or a balance of annual ion concentrations was maintained effectively with QP treatment compared to that of the control (Figure 2).

\subsection{Plant Growth}

A cool season species of komatsuna was used in our study. Leaf width and fresh weight of komatsuna plants were greater with QP treated nutrient solution compared to the control in all seasons, and both were significantly greater (significant at $\mathrm{P}=0.01$ for leaf width, and $\mathrm{P}=$ 0.05 for fresh weight) in the autumn season only (Table $3)$. Komatsuna plants in the winter grew more slowly but were about 2 to 3 times heavier compared to plants in the other seasons.

Leaf length of komatsuna was significantly greater in QP treatments compared to that of control for all seasons (Table 3). On average, komatsuna leaf growth rate was $16.6 \mathrm{~mm} /$ day for control and $17.3 \mathrm{~mm} /$ day for the QP treatment at 17 days after transplanting. Leaf growth rate was $7.3 \mathrm{~mm} / 4$ day in control and $11.7 \mathrm{~mm} / 4$ day in QP treatment the day before harvest. Some 2 to 3 days were

Table 3. Different growth attributes of komatsuna plants cultivated in control and QP treated nutrient solution in Kochi University, Nankoku city, Japan in different seasons from April 01, 2007 to February 27, 2008.

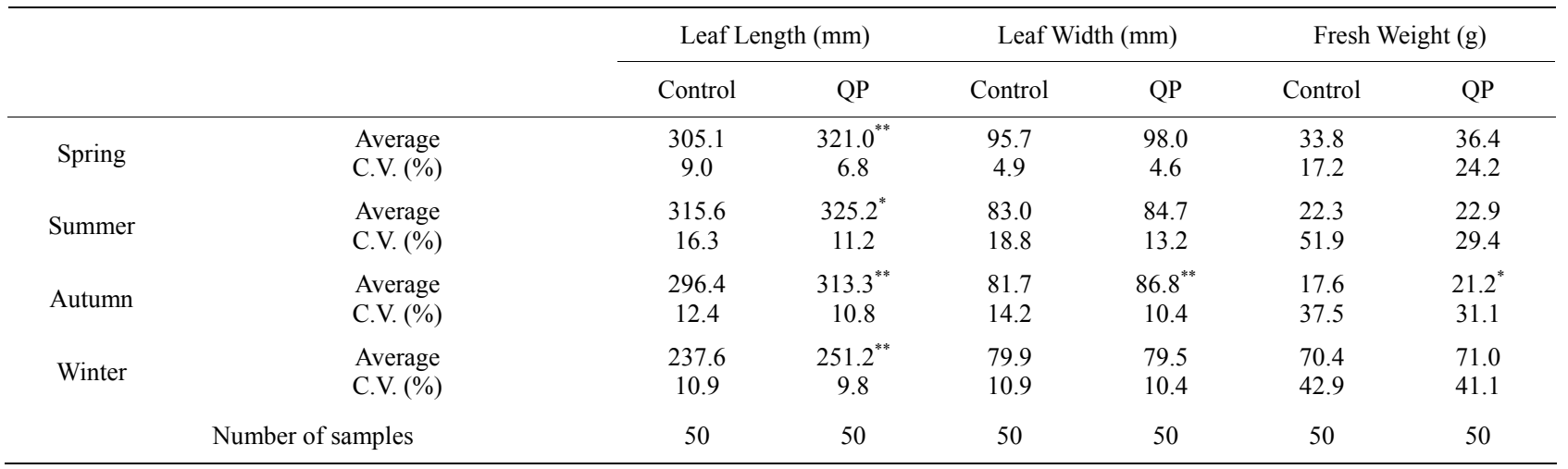

*Significant at $\mathrm{P}=0.05$ level; ${ }^{* *}$ Significant at $\mathrm{P}=0.01$ level; C.V. $=$ Coefficient of variation. 
Table 4. Ion analysis of tap/control water and quartz porphyry (QP) treated nutrient solution in producing komatsuna (Brassica rapa L.) hydroponically, Kochi University, Nankoku city, Japan in different seasons from April 01, 2007 to February $27,2008$.

\begin{tabular}{|c|c|c|c|c|c|c|c|c|c|}
\hline & & \multicolumn{8}{|c|}{ Ion concentrations $(\mathrm{meq} / \mathrm{L})$} \\
\hline & & $\mathrm{Na}^{+}$ & $\mathrm{K}^{+}$ & $\mathrm{Ca}^{2+}$ & $\mathrm{Cl}^{-}$ & $\mathrm{NO}_{3}^{-}$ & $\mathrm{SO}_{4}^{2-}$ & Total Cation & Total Anion \\
\hline \multirow{2}{*}{ April } & Tap Water & 0.24 & 0.02 & 0.68 & 0.16 & 0.08 & 0.20 & 0.94 & 0.44 \\
\hline & Treated Water & 0.23 & 0.02 & 0.86 & 0.10 & 0.04 & 0.07 & 1.11 & 0.31 \\
\hline \multirow{2}{*}{ May } & Tap Water & 0.24 & 0.02 & 0.58 & 0.13 & 0.06 & 0.17 & 0.84 & 0.37 \\
\hline & Treated Water & 0.23 & 0.02 & 0.57 & 0.16 & 0.08 & 0.19 & 0.83 & 0.42 \\
\hline \multirow{2}{*}{ June } & Tap Water & 0.27 & 0.04 & 0.93 & 0.17 & 0.09 & 0.20 & 1.24 & 0.45 \\
\hline & Treated Water & 0.26 & 0.03 & 0.57 & 0.22 & 0.06 & 0.20 & 0.86 & 0.49 \\
\hline \multirow{2}{*}{ July } & Tap Water & 0.27 & 0.03 & 1.48 & 0.26 & 0.13 & 0.23 & 1.78 & 0.61 \\
\hline & Treated Water & 0.25 & 0.03 & 1.04 & 0.22 & 0.06 & 0.25 & 1.31 & 0.52 \\
\hline \multirow{2}{*}{ Sep. } & Tap Water & 0.29 & 0.03 & 1.54 & 0.25 & 0.12 & 0.21 & 1.86 & 0.58 \\
\hline & Treated Water & 0.26 & 0.03 & 1.34 & 0.22 & 0.04 & 0.22 & 1.62 & 0.48 \\
\hline \multirow{2}{*}{ Oct. } & Tap Water & 0.34 & 0.04 & 1.33 & 0.22 & 0.17 & 0.22 & 1.71 & 0.61 \\
\hline & Treated Water & 0.31 & 0.04 & 1.16 & 0.22 & 0.01 & 0.19 & 1.50 & 0.43 \\
\hline \multirow{2}{*}{ Nov. } & Tap Water & 0.26 & 0.02 & 1.37 & 0.17 & 0.13 & 0.21 & 1.65 & 0.51 \\
\hline & Treated Water & 0.25 & 0.03 & 1.31 & 0.21 & 0.01 & 0.21 & 1.59 & 0.43 \\
\hline \multirow{2}{*}{ Dec. } & Tap Water & 0.26 & 0.03 & 0.97 & 0.16 & 0.09 & 0.21 & 1.26 & 0.46 \\
\hline & Treated Water & 0.24 & 0.03 & 0.91 & 0.20 & 0.00 & 0.18 & 1.17 & 0.39 \\
\hline \multirow{2}{*}{ Feb. } & Tap Water & 0.25 & 0.02 & 0.63 & 0.18 & 0.06 & 0.19 & 0.90 & 0.44 \\
\hline & Treated Water & 0.25 & 0.02 & 1.33 & 0.19 & 0.05 & 0.20 & 1.60 & 0.45 \\
\hline
\end{tabular}

Each value indicates the average of three (3) samples. Samples were taken at the same time at 10:00 am on every alternate day during the 30-day period of experiment.

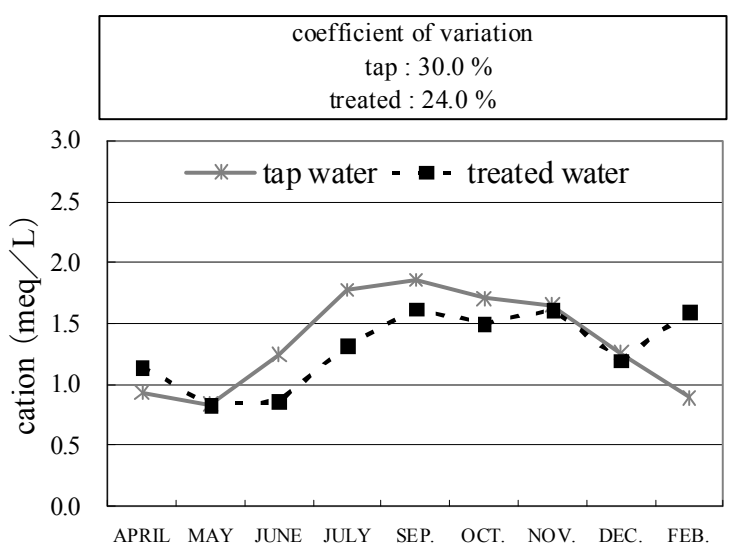

(a)

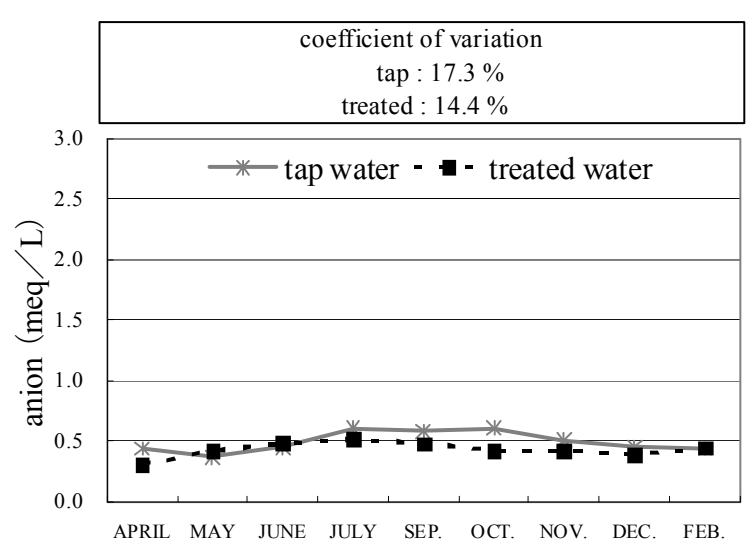

(b)

Figure 2. Change in the concentration of cations (a) and anions (b) in control (tap water) and QP treated nutrient solution in producing komatsuna (Brassica rapa L.) in Kochi University, Nankoku city, Japan in different seasons from April 01, 2007 to February 27, 2008.

required by the control $(296 \mathrm{~mm})$ to reach the leaf length of the QP treatment $(313.3 \mathrm{~mm})$ in autumn. In other words, early harvest for 2 or 3 days seemed to be possible in QP treatment.

In winter, leaf length did not reach $300 \mathrm{~mm}$ in length at harvest. The plants grew $3.8 \mathrm{~mm} /$ day in the control, and $5.7 \mathrm{~mm} /$ day in the QP treatment. About 3 to 4 days were needed by the control $(237.6 \mathrm{~mm})$ to reach the leaf length in the QP treatment $(251.2 \mathrm{~mm})$. Comparing the results, early harvest by 3 or 4 days seemed possible in QP treatment.

\subsection{Water Quality}

Water quality is different by region and by season, affecting the management of the nutrient solution in hydroponics culture and plant growth. In this study, the growth of komatsuna was improved (Table 3) using QP treated water under NFT cultivation in hydroponics.

In the recirculating nutrient solution, the cations $\mathrm{Na}^{+}$ and $\mathrm{Ca}^{2+}$ and the anions $\mathrm{Cl}^{-}$and $\mathrm{SO}_{4}^{2-}$ were dominant and turned the media saline (Table 4). While a recirculating hydroponic experiment (NFT) is going on, the running water/nutrient solution is decreasing gradually 
through evaporation and absorption of solution by roots with the increase of elapsing time. However, the density of water with different salt solutes $\left(\mathrm{Na}^{+}, \mathrm{Ca}^{2+}, \mathrm{Cl}^{-}, \mathrm{SO}_{4}^{2-}\right)$ increases with the decreasing of water in the system. As a result, the media becomes saline or salinity increases. Incrocci et al. [17] reported that accumulation of salts (e.g. $\mathrm{Na}^{+} \mathrm{Cl}^{-}$) in the recirculating nutrient solution in irrigation water is a problem, and the use of poor-quality water accelerates salinity build-up in the substrate and may produce negative effects on crops. Across the globe, the composition of salts in water varies widely. Typically, nutrient deficiencies can occur when plants are exposed to high amounts of sodium [18]. Certain ions such as $\mathrm{Na}^{+}$ can have a profound effect on calcium mobility and distribution within certain plant organs.

Little information is provided in the literatures regarding improvement of water quality using QP. We found that QP treatment improved water quality by adjusting the balance of ion concentrations throughout the whole cultivation year. Nutrient imbalances can result in saltstressed plants in various ways. Imbalances may result from the effect of salinity on nutrient availability, competitive uptake, transport or partitioning within the plant or may be caused by physiological inactivation of a given nutrient resulting in an increase in the plant's internal requirement for that element [19].

In solution cultures, ion imbalances may primarily result from competitive interactions. Salinity, dominated by $\mathrm{Na}^{+}$salts not only reduces $\mathrm{Ca}^{2+}$ availability but also affect the quality of both vegetative and reproductive organs. Salinity can directly affect nutrient uptake, such as $\mathrm{Na}^{+}$ reducing $\mathrm{K}^{+}$uptake or by $\mathrm{Cl}^{-}$reducing $\mathrm{NO}_{3}{ }^{-}$uptake [20]. Sodium inhibits the uptake of $\mathrm{K}^{+}$by interfering with $\mathrm{K}^{+}$ ion channels in the plasma membrane of the root and also competes with $\mathrm{K}^{+}$for binding sites, especially under high ratios $[21,22]$. In our experiment, $\mathrm{Na}^{+}$became lower in the QP treated nutrient solution compared to the control treatment.

Indeed, different ion uptake by the crop and the use of irrigation water with ions such as sodium and chloride scarcely required by the crop causes nutritional imbalance and makes it necessary to frequently replace the recirculating nutrient solution. Moreover, the crop may absorb large amounts of nutrients and this can be responsible for deleterious effects on crop yield and quality [23].

Quartz porphyry may improve growth of plants by maintaining the balance of ions in the nutrient solution and also reduce the application of fertilizer in NFT hydroponics.

\section{CONCLUSION}

In NFT hydroponics, the growth of komatsuna was promoted by using QP treated nutrient solution. It was observed that water treated with QP decreased the variation of ion concentrations in culture solution throughout the year. Quartz porphyry adjusted the ion balance in water that influenced the growth and development of komatsuna plants. It is therefore, recommended to use QP water treatment to stabilize the improved production of quality plants in hydroponic culture.

\section{REFERENCES}

[1] Bugbee, B. (2004) Nutrient management in recirculating hydroponic culture. Acta Horticulture, 648, 99-112.

[2] Hoagland, D.R. and Arnon, D.I. (1938) The water culture method for growing plants without soil. California Agricultural Experiment Station Circulation, 347, 32.

[3] Resh, H.M. (2004) Hydroponic food production: A definite guidebook of soilless food growing methods. 6th Edition, Newconcept Press, Mahwah, 25.

[4] Ishikawa, K., Okada, Y. and Nakamura, J. (1995) Physical and chemical properties of Bakuhan-seki (Japanese text with English abstract). Journal of Japanese Society of Agricultural Machinery, 57, 51-56.

[5] Tanabe, K., Shinmura, Y., Yasuda, M., Shinma, K., Nakamura, H. and Ishikawa, K. (1994) The effects of various water on early growth in plants 1 . Journal of SHITA, 6, 147-152.

[6] Tanabe, K., Wakisaka, T., Yasuda, M., Shinma, K. and Ishikawa, K. (1995) The effects of various water on early growth in plants (Part 2)-Effects of $\mathrm{pH}$ and ultrasonic treatment on water. Journal of SHITA, 7, 185-190.

[7] Umeki, T. and Ishikawa, K. (1996) The effects of various water on growth in plants (Part 2)-Influence of water on plant tissue. Journal of SHITA, 8, 292-296.

[8] Ablaza, E.C., Ishikawa, K. and Yoshimura, T. (2006) Effects of quartz porphyry (Bakuhan-seki) on soil quality and grain yield of wheat (Triticum aestivum L.). Journal of Food Agriculture and Environment, 4, 270-275.

[9] Nakamura, H., Ishikawa, K., Okada, Y., Tanabe, K. and Gejima, Y. (1996) Fundamental studies on the activation of water using mineral (part 1) (in Japanese). Journal of Japanese society of Agricultural Machinery, 58, 235-241.

[10] Ishikawa, K. and Nakamura, H. (1999) Functional treatment system for water used in greenhouses. The Journal of the Society of Agricultural Structures, 29, 225-229.

[11] Cooper, A. (1979) The ABC of NFT: Nutrient film technique. Grower Book, London.

[12] Farnham, D.S., Hasek, R.F. and Paul, J.L. (1995) Water quality its effects on ornamental plants. University of California, Berkeley.

[13] Duncan, D.B. (1955) Multiple ranges and multiple F-test. Biometrics, 11, 1-42. doi:10.2307/3001478

[14] Hayashi, M. (2004) Temperature-electrical conductivity relation of water for environmental monitoring and geophysical data inversion. Environmental Monitoring and Assessment, 96, 119-128. 
doi:10.1023/B:EMAS.0000031719.83065.68

[15] Al-Ghamdi, S.S. and Al-Tahir, O.A. (2001) Temperature and solar radiation effect on faba bean (Vicia faba L.) growth and grain yield. Saudia Journal of Biollogical Science, 8, 171-182.

[16] TPS Pty Ltd. (2013) pH in hydroponics. TPS Quality Service Value.

http://www.tps.com.au/hydroponics/pheffect.htm

[17] Incrocci, L., Malorgio, F., Della, A.B. and Pardossi, A. (2006) The influence of drip irrigation or subirrigation on tomato grown in closed-loop substrate culture with saline water. Scientia Horticulturae, 107, 365-372. doi:10.1016/j.scienta.2005.12.001

[18] Carter, C.T. and Grieve, C.M. (2008) Mineral nutrition, growth, and germination of Antirrhinum majus L. (Snapdragon) when produced under increasingly saline conditions. HortScience, 43, 710-718.

[19] Grattan, S.R. and Grieve, C.M. (1994) Mineral nutrient acquisition and response by plants grown in saline envi- ronments. In: Passarakil, M., Ed., Handbook of Plant and Crop Stress, Marcel Dekker, New York, 203-226.

[20] Grattan, S.R. and Grieve. C.M. (1998) Salinity-mineral nutrient solutions in horticultural crops. Scientia Horticulturae, 78, 127-157. doi:10.1016/S0304-4238(98)00192-7

[21] Maathuis, F.J.M. and Amtmann, A. (1999) $\mathrm{K}^{+}$nutrition and $\mathrm{Na}^{+}$toxicity: The basis of cellular $\mathrm{K}^{+} / \mathrm{Na}^{+}$ratios. Annals of Botany (London), 84, 123-133. doi:10.1006/anbo.1999.0912

[22] Tester, M. and Davenport, R. (2003) $\mathrm{Na}^{+}$tolerance and $\mathrm{Na}^{+}$transport in higher plants. Annals of Botany (London), 91, 503-527. doi:10.1093/aob/mcg058

[23] Pardossi, A., Malorgio, F., Incrocci, L., Campiotti, C.A. and Tognoni, F. (2002) A comparison between two methods to control nutrient delivery to greenhouse melons grown in recirculating nutrient solution culture. Scientia Horticulturae, 92, 89-95. doi:10.1016/S0304-4238(01)00292-8 